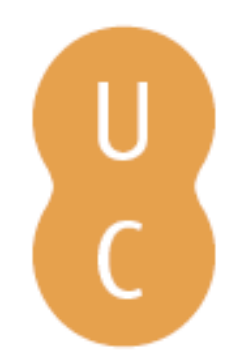

\title{
pompalina
}

\section{Em torno da revisão do sistema eleitoral açoriano}
Autor(es):
Amaral, Carlos E. Pacheco
Publicado por: Imprensa da Universidade de Coimbra
URL persistente:
URI:http://hdl.handle.net/10316.2/47292
DOI:
DOI:https://doi.org/10.14195/978-989-26-1849-4_1

Accessed : $\quad$ 26-Apr-2023 04:50:55

A navegação consulta e descarregamento dos títulos inseridos nas Bibliotecas Digitais UC Digitalis, UC Pombalina e UC Impactum, pressupõem a aceitação plena e sem reservas dos Termos e Condições de Uso destas Bibliotecas Digitais, disponíveis em https://digitalis.uc.pt/pt-pt/termos.

Conforme exposto nos referidos Termos e Condições de Uso, o descarregamento de títulos de acesso restrito requer uma licença válida de autorização devendo o utilizador aceder ao(s) documento(s) a partir de um endereço de IP da instituição detentora da supramencionada licença.

Ao utilizador é apenas permitido o descarregamento para uso pessoal, pelo que o emprego do(s) título(s) descarregado(s) para outro fim, designadamente comercial, carece de autorização do respetivo autor ou editor da obra.

Na medida em que todas as obras da UC Digitalis se encontram protegidas pelo Código do Direito de Autor e Direitos Conexos e demais legislação aplicável, toda a cópia, parcial ou total, deste documento, nos casos em que é legalmente admitida, deverá conter ou fazer-se acompanhar por este aviso.

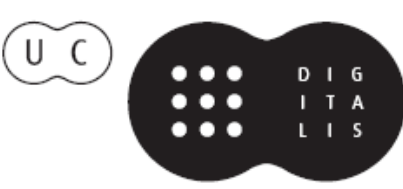


Euro-Atlântico:

Espaço de Diálogos

Isabel Maria Freitas Valente

Iranilson Buriti de Oliveira

(Coord)

\section{VISÕES \\ INTERDISCIPLINARES \\ DA EUROPA \\ E DO MUNDO:}

uma experiência de convergência

disciplinar em homenagem a

Maria Manuela Tavares Ribeiro

Alexandra Aragão

Isabel Maria Freitas Valente

Dulce Lopes

(org.)

Editora da Universidade Federal de Campina Grande

Imprensa da Universidade de Coimbra

2019 


\title{
EM TORNO DA REVISÃO DO SISTEMA ELEITORAL AÇORIANO
}

\author{
Carlos E. Pacheco Amaral, PhD \\ Universidade dos Açores | Ceis 20 \\ E-mail: carlos.ep.amaral@uac.pt
}

À Senhora Professora Doutora Maria Manuela Tavares Ribeiro, em preito de homenagem pela imponente carreira académica que tem vindo a desenvolver e de gratidão pelo precioso apoio que nos tem vido a oferecer.

\section{Resumo}

O texto parte de um duplo exercício. Por um lado, das funções exigidas de um sistema eleitoral nas democracias contemporâneas e, por outro lado, da apresentação das principais linhas de força do actual sistema político e eleitoral da Região Autónoma dos Açores. Confrontando a realidade concreta açoriana com o ideário democrático e com os princípios fundamentais da autonomia política, em termos da respectiva projecção externa, nacional, europeia e internacional, mas também em termos da sua projecção interna, nas ilhas que enformam a Região, pretende-se contribuir para o processo, em curso, de revisão dos sistema político e eleitoral dos Açores, identificando as principais correcções e inovações que importa introduzir.

Palavras-chave: Açores; Autonomia; Democracia.

\section{Abstract}

The text is grounded upon a double exercise. On the one hand, the revisiting of the functions required by the contemporary democracies of an electoral system and, on the other hand, the presentation of the major guidelines of the present political and electoral system of the Autonomous Region of the Azores. Confronting Azorean reality with the democratic ideal and with the fundamental principles of political 
autonomy, in terms of its external projection, national, European and international, as well as in terms of its internal projection, at the level of the islands that, together, make up the Region as a whole, allows us to develop the present contributions to the ongoing (?) process of revision of the political and electoral system of the Azores, identifying the major corrections and innovations that need to be introduced.

Keywords: Azores; Autonomy; Democracy.

De um sistema eleitoral esperar-se-á, em democracia, que seja capaz de produzir uma classe política, um Legislativo, e, a partir dele, um Executivo, que correspondam, que espelhem a própria comunidade a que se reporta, bem como o regime político que a enforma. Espera-se, não a garantia da representação parlamentar deste ou daquele partido político, associação cívica ou agrupamento concreto de cidadãos, a ascensão ao poder daquele outro, ou a produção deste ou daquele equilíbrio parlamentar, mas a garantia de que os resultados eleitorais traduzem, de facto, a vontade popular dos cidadãos. Paralelamente, um sistema eleitoral deverá ainda assegurar três funções nucleares. Em primeiro lugar, conquistar a lealdade dos cidadãos para com o regime político e, por essa via, potenciar a participação democrática. Em segundo lugar, assumindo uma dimensão responsiva, garantir que as opções políticas adoptadas não decorrem da vontade mais ou menos arbitrária dos eleitos, mas antes correspondem à vontade dos cidadãos, imprimindo-lhes forma concreta no debate político. Por fim, e em terceiro lugar, deverá oferecer amplas ocasiões de responsabilização dos agentes políticos perante os cidadãos pelas opções políticas que adoptam em cada momento, e não apenas pelas promessas, mais ou menos vagas, apresentadas nos períodos eleitorais.

Neste termos, o sistema eleitoral açoriano não poderá deixar de ter presente duas coisas. Em primeiro lugar que, em vez de uma Região continental homogénea, os Açores são uma Região arquipelágica, complexa e plural, e que os açorianos, em vez de absolutamente iguais uns aos outros, em tudo, vêem a sua identidade, os seus interesses e 
as suas próprias vidas serem indelevelmente marcadas pelas unidades onde nasceram, se inserem e desenvolvem as suas vidas: as ilhas (a par de uma variedade de outras dimensões, bem sei, como é o caso, em particular da dimensão municipal). E, em segundo lugar, que os Açores não são comparáveis a qualquer outro espaço, como a Amadora ou a Região Centro do país, por exemplo. Pelo contrário, constituem uma Região que é e se quer autónoma, tanto na sua relação com o resto do Estado português e com a União Europeia, como na sua organização social e política interna - já que os princípios da autonomia e da subsidiariedade são tão válidos para a relação dos Açores com a União Europeia e com o Estado português, como para a própria organização política interna do arquipélago, isto é, para a sua organização em freguesias e em municípios, para a organização de freguesias e de municípios em ilhas e das ilhas na Região (para a sua organização e para o seu inter-relacionamento).

O paradigma de comunidade política dominante no Ocidente, pelo menos desde a Revolução Francesa, assenta na perspectiva segundo a qual a comunidade se constrói a partir da celebração de um contrato entre todos. Não de um contrato qualquer, mas de um contrato social, nos termos do qual os indivíduos perdem a identidade privativa que dantes possuíam e adoptam todos, em comum, a nova identidade que lhes é proposta pela comunidade, no caso concreto da modernidade, pelo Estado. Daí que, pelo contrato social, se passe de um registo individualista (em que nos deparamos com uma multiplicidade de pessoas, todas diferentes, na medida em que cada uma é detentora de uma identidade, interesses e valores que lhe são privativos), para o registo estatal (em que encontramos sujeitos iguais, tornados iguais por força do contrato social). É assim que, segundo o paradigma da modernidade, todos os membros do Estado são absolutamente iguais. E ainda hoje nos confrontamos com a condição de, enquanto membros do Estado português, isto é, enquanto cidadãos portugueses, sermos todos iguais - sem prejuízo, naturalmente, das especificidades que podemos apresentar em termos das nossas vidas privadas. Numa palavra, enquanto cidadãos privados podemo-nos diferenciar uns dos outros, 
ser casados ou solteiros, por exemplo, preferir carne, ou peixe, ou ser vegetarianos, ser católicos, protestantes, ou agnósticos, etc., etc. Já enquanto cidadãos, somos todos iguais, na medida em que somos todos sujeitos de um mesmo corpo de direitos fundamentais e conduzimos as nossas vidas no quadro de um mesmo corpo de direito civil, de direito criminal, etc., etc.

Foi por isso que a modernidade procedeu à abolição do "mandato imperativo", isto é, da vinculação do deputado à circunscrição que o elegeu, passando a vincular todos os deputados a uma mesma identidade, a nacional, e a uma mesma vontade, a vontade geral do Estado. E é por isso também que, para a modernidade, os círculos eleitorais assumem um valor estritamente técnico, já que a sua delimitação tem por base critérios de eficácia apenas. É igualmente esta a razão subjacente ao princípio de que, para a modernidade, o deputado representa, não o círculo eleitoral por que foi eleito, mas a comunidade, no seu todo.

Ora, convém sublinhar que o paradigma moderno de soberania estatal não tem qualquer lugar para princípios como os de autonomia política regional ou de subsidiariedade. Desde logo pela razão tão simples quanto evidente que admitir o princípio de autonomia política equivaleria a reconhecer que a nação não é um todo homogéneo, mas que conhece partes, as quais se reclamam, ou se querem reclamar, desse princípio. Admitir o princípio de autonomia política equivale a reconhecer que, no quadro da unidade nacional, o Estado integra partes, as quais conhecem uma identidade privativa e interesses que lhes são específicos também. E é precisamente o acesso destas partes, enquanto tais, ao poder político que o princípio de autonomia política vem exigir. Paralelamente, a admissão do princípio de autonomia exige o princípio correlativo de subsidiariedade, isto é, de partilha do poder político entre o centro e as entidades regionais.

Em termos de sistema eleitoral, reconhecer os princípios de autonomia e de subsidiariedade equivale, portanto, a recusar dois postulados de base da modernidade. Por um lado, o carácter artificial dos círculos eleitorais. A autonomia parte do princípio de que, no quadro do todo nacional, existem sujeitos sociais que pretendem afirmar-se 
como sujeitos políticos também, isto é, como autónomos. Daí que os círculos eleitorais se devam revestir de uma dimensão real e objectiva, correspondendo ao ser que é próprio das entidades autónomas. Em vez de artificiais, isto é, em vez de decorrerem do cálculo que, a propósito, o Estado vier a fazer em termos de eficácia governativa, os círculos eleitorais deverão corresponder à dimensão, às fronteiras das unidades sociais e políticas que se manifestam. No caso português, entre estas unidades destacam-se, a nível nacional, as Regiões Autónomas. A nível da União Europeia os Estados afirmam-se com idêntica objectividade. E, nos Açores, a nível interno, regional, são as ilhas e, nestas, os municípios e as freguesias que se impõem como sujeitos reais e incontornáveis. Paralelamente, e pelas mesmas razões, a nível interno, cada uma das ilhas açorianas detém um ser objectivo e uma dignidade que não lhe é outorgada do exterior mas que lhe é intrínseca, apresentando-se, por isso, como um ente político que, em termos de sistema eleitoral, importa reconhecer e enformar.

É neste contexto que, ao nível da União Europeia, seria absolutamente impensável forjar um sistema político e eleitoral no qual os Estados não tivessem lugar. De igual modo, e já ao nível nacional, seria impensável, nas eleições para a Assembleia da República, eliminar o círculo regional dos Açores e, por exemplo, acoplar a ilha de Santa Maria ao círculo de Braga, São Miguel ao do Porto, a Terceira ao do Évora, o Faial ao de Lisboa, o Corvo ao de Faro, e por aí adiante. Ou, pior, num tal exercício de reconfiguração, nem atender à realidade e distribuir os cidadãos por círculos eleitorais de forma aleatória, produzindo círculos exactamente iguais, que integrassem o mesmo número de homens e de mulheres, de casados e de solteiros, de analfabetos e de doutorados, de católicos e de protestantes, de profissionais das várias carreiras, etc., etc.

Ora, exactamente pelas mesmas razões, torna-se também um contra-senso pensar um sistema eleitoral para os Açores que não parta das unidades sociais que compõem a Região, as ilhas e, nelas, os municípios e as freguesias. Assim, acoplar a Vila do Corvo a Santa Cruz, ou a toda a ilha das Flores, ou reunir todas as ilhas num círculo 
regional único, sejamos claros, seria equivalente a acoplar a ilha do Pico ao Distrito de Beja ou de Coimbra, por exemplo, para a constituição de um círculo eleitoral para a Assembleia da República, ou à associação de Portugal ao Luxemburgo ou a Malta, por exemplo, na constituição de um círculo eleitoral para o Parlamento Europeu. De igual modo, fundir todas as ilhas num círculo regional único (negando a identidade privativa de cada uma delas) equivale à construção de um círculo nacional único para a Assembleia da República, ou à fusão de todos os Estados-membros da União Europeia na criação de um círculo europeu único, para o Parlamento.

Importa aqui sublinhar um segundo aspecto que passamos a expor. O século XIX ofereceu-nos o modelo da Revolução Francesa, mas disponibilizou nos também um modelo alternativo, também ele de origem revolucionária, proveniente do outro lado do Atlântico, a Revolução Norte-Americana. A Revolução Francesa ofereceu-nos o modelo jacobino, centralizador, de homogeneidade e de unidade absolutas do Estado. Com a Revolução Norte-Americana assistiu-se à consolidação de outro modelo, alternativo, diríamos girondino, federal, assente sobre um paradigma nos termos do qual o Estado, em vez de se apresentar como um todo homogéneo e absolutamente uno, emerge como um todo de ordem, que conhece partes, às quais se torna necessário, portanto, garantir um lugar, quer no regime de organização política, quer no próprio sistema eleitoral que o enforma.

Neste contexto, um sistema eleitoral constitui mais do que uma fórmula abstracta de fixação do modo como se deverá seleccionar aqueles a quem a sociedade confia o poder. Antes dele exige-se que decorra, simultaneamente, do tipo de comunidade a que se reporta, das características que a enformam, e do modelo social e político de que essa comunidade se reclama. No caso concreto dos Açores, o sistema eleitoral terá de decorrer, por um lado, da condição arquipelágica da Região e do valor representado pelas suas ilhas e, nelas, pelos seus municípios e pelas suas freguesias, e, por outro, do princípio de autonomia, ou melhor, dos princípios de autonomia e de subsidiariedade que enformam a vida social e política da região e dos quais, segura- 
mente, ela não pretende abdicar. Sendo certo que os mesmos princípios que servem para nortear a inserção social e política da região no quadro nacional e no quadro europeu, são igualmente válidos e pertinentes para a definição da sua própria organização política interna.

Acresce ainda um aspecto adicional importante. Na medida em que as circunscrições de base territorial que constituem a comunidade política não são uma construção artificial do Estado, antes se lhe impõem, desde logo na medida em que apresentam um ser e uma identidade privativas e se reclamam da sua autonomia política, elas jamais poderão ser todas iguais. Isto é, na medida em que abdicarmos da pretensão positivista da modernidade, nos termos da qual é a comunidade política que constrói a comunidade social em que assenta, e, portanto, é o Estado que constrói a nação, vemo $\urcorner$ nos forçados a reconhecer a pluralidade e a diversidade sociais, tal como se nos apresentam: uma pluralidade e diversidade que, nalguns aspectos, podem ser corrigidas, é certo - podem e devem, como acontece quando nos reportamos ao desenvolvimento económico e à qualidade de vida. Trata-se, porém, de uma pluralidade e de uma diversidade que, noutros aspectos, se encontram para além da capacidade humana de intervenção, pelo menos por enquanto. (Não é possível, mesmo que isso fosse desejável, fazer crescer as nossas ilhas, torná-las todas do mesmo tamanho, alargando-as para a dimensão da Inglaterra, por exemplo, aproximá-las umas das outras, ou do continente português, aplainar as nossas montanhas ou endireitar as encostas das ilhas, etc. Do mesmo modo que não é possível tornar os portugueses todos da mesma estatura, com o mesmo coeficiente de inteligência, ou atribuir a todos exactamente a mesma aparência física.)

Ao nível das identidades e da cultura, por exemplo, jamais consentiríamos que o projecto europeu passasse pela substituição das nossas identidades e culturas nacionais por uma identidade e uma cultura europeia amorfa única (quiçá através de um processo semelhante àquele pelo qual, ao nível da integração económica, se procedeu à construção do Mercado Comum e, a nível financeiro, na Zona Euro, à substituição das moedas nacionais por uma moeda europeia única, o Euro). De 
igual modo, não se afigura aceitável que a identidade portuguesa dos açorianos se produza a expensas da sua identidade açoriana. Aliás, é essa identidade, essa especificidade regional, que justifica e que legitima a autonomia política. É a própria Constituição da República que o reconhece. E, ao nível interno da Região, tão-pouco se afigura desejável substituir a identidade de cada uma das ilhas açorianas por uma identidade única amorfa comum.

Para além disso, urge ter presente, com clareza, o seguinte aspecto. A nossa identidade portuguesa e a salvaguarda dos nossos interesses nacionais não diminui a nossa identidade europeia e a condição de membros da União Europeia, de cidadãos europeus de corpo inteiro. Pelo contrário, é porque somos portugueses que somos europeus. Isto é, a identidade europeia não passa pela negação da identidade portuguesa, antes decorre dela. E, na relação entre a Região e o Estado verifica-se algo muito semelhante. A açorianidade, a identidade açoriana e a defesa dos interesses da Região não constituem uma qualquer diminuição, muito menos uma negação da identidade nacional portuguesa. Pelo contrário, é porque somos açorianos que somos portugueses.

Ora, é precisamente o mesmo que se passa ao nível interno, na relação entre o todo, Região Autónoma dos Açores, e as partes que a constituem, as ilhas. A nossa identidade como micaelenses, marienses, florentinos ou corvinos, jamais poderá ser perspectivada como acarretando uma qualquer diminuição, muito menos uma negação, da nossa identidade comum açoriana.

A unidade regional não pode ser perspectivada, à maneira da modernidade, como uma unidade absolutamente una. Antes, e no quadro da melhor tradição regionalista e autonomista da Europa, tem de ser vista como uma unidade de ordem, plural e diversificada, porque plural e diversificada é a realidade social que lhe está na base. Uma unidade que decorre do encadeamento subsidiário de ilhas, de municípios e de freguesias. Por isso é que, em vez de absolutamente una, homogénea e inconsútil, a Região Autónoma dos Açores deverá apresentar-se 
como uma federação de ilhas e de municípios autónomos encadeados subsidiariamente.

$\mathrm{Na}$ base do argumento regionalista e autonomista encontramos a reivindicação de que à pluralidade e diversidade social corresponda uma idêntica pluralidade e diversidade política também. $\mathrm{O}$ argumento regionalista e autonomista reclama que o sistema de organização social e política reserve um papel para cada um dos elementos sociais que, encadeados subsidiariamente, produzem a comunidade política global - sem permitir que a comunidade superior absorva, à maneira da modernidade, as comunidades inferiores que possa integrar. É assim que, no quadro da União Europeia, haverá que reservar um lugar para os Estados que a integram; que o Estado Português tem de reservar um lugar para a Região Autónoma dos Açores que dele faz parte integrante; da mesma maneira que, na sua organização política interna, a Região terá de consagrar um lugar para as suas ilhas.

Por outras palavras, diríamos que nos encontramos perante nada menos de que uma autêntica pulverização do já velho conceito de cidadania! A cidadania poderá ser entendida como expressão de identidade, de pertença a uma comunidade política. Assim, ao mesmo tempo que estabeleceu apenas uma categoria de comunidade política, o Estado, a modernidade reconheceu apenas uma categoria de cidadãos. E, tal como só podemos ser membros de uma comunidade política, também só podemos ser cidadãos de um Estado. Tanto assim que, para a modernidade, a cidadania múltipla, no fundo, pouco mais é do que uma ficção. E é este o contexto em que a democracia se desenrola apenas a um nível, estatal, e a participação democrática se situa exclusivamente ao nível do exercício do direito de voto, que é igualmente um dever, por parte de cidadãos todos perfeitamente iguais entre si na medida em que partilham de uma mesma identidade que lhes havia sido impressa pelo Estado.

Com a contemporaneidade assiste-se à projecção da cidadania, para além e para aquém do Estado, para todas as unidades sociais em que nos inserimos. No nosso caso, desde a União Europeia, no topo, até à Região, e à ilha, na base, passando, como é óbvio, pelo Estado. Na 
medida em que, nos nossos dias, somos simultaneamente membros de uma panóplia de comunidades sociais, a democracia exige uma representação e uma participação ao nível de cada uma delas. No quadro da União Europeia não basta uma participação democrática de todos enquanto cidadãos europeus, exige-se uma participação democrática dos europeus enquanto cidadãos deste ou daquele Estado. De igual modo, a nível nacional, a nós açorianos, não nos basta uma participação democrática enquanto cidadãos portugueses iguais, todos, uns aos outros, exigimos uma participação democrática própria enquanto açorianos - daí, aliás, a autonomia política regional. E também a participação democrática regional deve operar $\urcorner$ se a dois níveis: unitário enquanto membros da Região, enquanto um todo, e plural, enquanto membros desta ou daquela ilha.

Nos nossos dias, a concepção moderna de cidadania, reduzindo $\urcorner$ se ao Estado e integrando um conjunto de cidadãos todos absolutamente iguais, cede lugar a uma concepção de cidadania nova, assente sobre a pluralidade de comunidades em que nos situamos e que nos individualizam, fazendo com que sejamos, simultaneamente, iguais e diferentes. Iguais, nalguns aspectos fundamentais, e diferentes noutros, precisamente naqueles que nos individualizam. É assim que, enquanto cidadãos europeus, somos todos iguais, se bem que sejamos também diferentes, perspectivados enquanto portugueses, espanhóis, finlandeses ou polacos; que, enquanto cidadãos portugueses, somos todos iguais, se bem que sejamos igualmente diferentes, quando perspectivados como lisboetas, madeirenses ou açorianos. E o mesmo se passa a nível regional. Enquanto açorianos, somos todos iguais, mas somos também todos diferentes, enquanto micaelenses, jorgenses ou corvinos. São as novas dimensões da cidadania, às quais, obviamente, o sistema eleitoral que desenharmos tem que corresponder e dar resposta, a risco de se alienar da sociedade real e dos próprios cidadãos.

No quadro do paradigma autonomista e regionalista que nos tem norteado, diríamos que a comunidade política se apresenta como um todo unitário, composto por iguais, apenas em dois registos: externo e interno. Perante o exterior, isto é, ao nível da participação dessa 
comunidade nos todos, nas comunidades políticas, superiores que integrar. E, a nível interno, no quadro axiológico fundamental responsável pela sua identidade e pelo seu próprio ser, isto é, em face dos valores e de direitos tidos por fundamentais que reúnem e aglutinam as partes que a constituem.

É assim que a União Europeia se constitui como um todo e enquanto cidadãos europeus, todos somos iguais, fundamentalmente em dois contextos: perante o exterior, isto é, na relação com Estadosterceiros, e no quadro dos direitos fundamentais de que todos nos reclamamos, nomeadamente aqueles consagrados na Carta dos Direitos Fundamentais da União. Em todo o restante, emerge a nossa identidade nacional, como portugueses, alemães ou húngaros.

O Estado apresenta-se como um todo unitário, apenas ao nível da sua participação no todo superior que é a União Europeia; no seu seio reconhece as partes que o integram, inclusivamente ao nível político. Ao nível nacional, português, todos somos iguais, na relação com o exterior, com outros Estados, e no quadro dos direitos fundamentais plasmados na Constituição e na legislação fundamental da República. Em tudo o mais, aquilo que emerge é a nossa identidade regional, isto é, o quadro político que adoptamos autonomamente.

Do mesmo modo, enquanto açorianos, todos somos iguais, na relação com o exterior, com as demais Regiões, do país e da Europa, e no quadro dos direitos fundamentais definidos para a totalidade da comunidade regional açoriana. No resto, a nível interno, o que sobressai são as nossas identidades insulares, desta ou daquela ilha, que nos especificam e nos diferenciam.

Por esta razão, em matéria de círculos eleitorais, uma comunidade política apresenta-se como uma unidade, devendo, por isso, constituir um círculo eleitoral único, apenas ao nível da sua participação nos todos superiores que integra. Em termos da sua projecção para o exterior, o Estado português, por exemplo, constitui um círculo único, já que a este nível todos somos iguais, como se verifica, por exemplo, em termos de eleições para a União Europeia. Mas já naquilo que à sua organização política interna diz respeito, prevê uma pluralidade 
de registos e uma pluralidade de círculos, que devem corresponder à pluralidade social que lhe está subjacente - como paradigmaticamente se verifica no caso dos círculos eleitorais dos Açores e da Madeira nas eleições para a Assembleia da República.

De igual modo, ao nível regional, os Açores constituem uma unidade apenas perante o exterior. No seu seio, a palavra de ordem terá que ser, sempre, a pluralidade e a individualidade. Daí que, em termos de círculos eleitorais, deva constituir igualmente uma unidade apenas quando estiver em causa a sua participação democrática no exterior, nomeadamente nos órgãos de poder gerais do Estado português. A esse nível, os açorianos são todos iguais, e, perante o Estado, os Açores constituem uma unidade. Assim, é justa a previsão de um círculo único para identificação daqueles açorianos que ficarão encarregados de representar a Região no todo estatal. Já a nível interno, aquilo que se impõe não é a unidade, mas a pluralidade, ou, melhor, a unidade na pluralidade. Por conseguinte, os círculos eleitorais devem ser da dimensão das comunidades insulares que, no seu conjunto, constituem o todo regional. E esta concepção leva-nos igualmente a rejeitar inequivocamente quaisquer propostas de círculos regionais a nível interno, nomeadamente para a Assembleia Legislativa Regional. O círculo regional só faz sentido a nível externo - a nível interno, são os círculos de ilha que se impõem.

$\mathrm{E}$, neste contexto, faria um parêntesis, para invocar a décima ilha do arquipélago dos Açores. As comunidades emigrantes açorianas espalhadas pela diáspora como que oferecem à Região uma ilha adicional, uma décima ilha, na qual se assiste, como por magia, aos dois processos inter-relacionados seguintes. Em primeiro lugar, ao esboroamento das fronteiras que, na Região, separam as ilhas umas das outras. À aproximação das nove ilhas originais do arquipélago que permaneceram firmes no Atlântico norte. E, mais do que isso, à fusão destas ilhas através do convívio diário entre as suas gentes. Do convívio entre corvinos, que vivem na mesma cidade, e, muitas vezes, no mesmo bairro e até no mesmo prédio, e micaelenses, terceirenses, faialenses e, no limite, concidadãos provenientes de todas as ilhas do 
arquipélago. E, em segundo lugar, à emergência de uma identidade açoriana radicalmente inovadora porque assente na assimilação, na fusão das identidades particulares de ilha que cada uma havia transportado consigo.

Não nos choca, obviamente, que um algarvio, um minhoto ou um lisboeta que venha para os Açores e aqui queira ficar seja contabilizado como açoriano e detenha o direito de votar, de eleger e de ser eleito, na identificação daqueles que deverão representar politicamente os açorianos, seja na Assembleia Legislativa Regional dos Açores, seja na Assembleia da República, ou nas demais instâncias em que nos inserimos. O que não se entende é que pelo facto de atravessar o Atlântico, uma pessoa perca a sua condição de açoriano. Muito em particular quando esses emigrantes espalhados pela diáspora projectam os Açores no mundo, oferecendo- lhe uma dimensão que, aproveitada, poderá constituir uma alavanca preciosa para o seu processo de desenvolvimento, já que assegura à Região uma dimensão verdadeiramente global.

Urge reconhecer que, na verdade, o actual sistema eleitoral dos Açores é contestado, e bem. No entanto, convém identificar com precisão onde é que o problema se coloca, de modo a que a cura não seja pior do que a doença. E, por outro lado, será igualmente conveniente aproveitar a reforma para o aperfeiçoamento global do sistema autonómico, contexto em que, para além da questão de proporcionalidade, se torna necessário introduzir na reflexão ainda outras variáveis, como sejam as da representatividade, da transparência, da aproximação dos eleitos aos eleitores e, em última instância, da participação democrática.

O principal problema do sistema eleitoral actualmente em vigor, prende-se com o facto de poder produzir legitimidades democráticas contraditórias. No quadro do actual sistema eleitoral é possível um partido ganhar as eleições, em termos de número de votos, isto é, ter mais votos, e, ao mesmo tempo, perdê-las, em termos de mandatos, isto é, ter menos deputados na Assembleia. Quer isto dizer que o actual sistema permite que dois partidos se reclamem de legitimidade democrática para formarem governo: um, por ter tido mais votos, e 
outro por ter obtido mais deputados, e, eventualmente, até mesmo uma maioria parlamentar - e, como se sabe, não é de uma questão meramente académica que se trata, mas de um perigo bem real.

É este o problema nuclear do sistema eleitoral açoriano, o qual não decorre do facto de as ilhas do arquipélago constituírem círculos eleitorais, nem do facto de lhes ser atribuída uma representação. Os dois deputados consignados a cada ilha não se traduzem num contingente mínimo. Antes, constituem um tipo específico de deputados. São representantes de ilha. Procuram levar para o Parlamento açoriano a pluralidade subjacente à Região. São deputados de representação territorial, tal como os Senadores norte-americanos, ou os membros do Bundesrat alemão.

$\mathrm{Na}$ verdade, o actual sistema eleitoral açoriano consagra dois tipos diferentes de deputados. Os deputados de representação territorial, que são dezoito, dois em representação de cada uma das nove ilhas do arquipélago, e os deputados de representação demográfica, que são os demais. Nos Estados Unidos, por exemplo, parte-se do princípio de que, em termos políticos, não há Estados mais importantes do que outros, postulando-se, antes, a igualdade entre todos, independentemente da sua dimensão geográfica, da sua população ou da sua pujança económica. Também entre nós se parte do princípio de que não há ilhas mais importantes do que outras, pelo contrário, todas possuem igual dignidade, independentemente da sua dimensão, da sua população ou da sua capacidade económica. Aliás, se alguma coisa as ilhas mais pequenas ou mais frágeis, já se encontram suficientemente penalizadas, pela sua reduzida dimensão, aos mais variados níveis, social, económico, cultural, recreativo, ... Não necessitam, portanto, que lhes seja imposta uma penalização adicional, desta vez de índole política. Daí que, tal como nos Estados Unidos, dada a sua importância política e igual dignidade, cada Estado elege dois Senadores, também nos Açores, dada a sua importância social e igual dignidade política, cada ilha elege dois deputados à Assembleia Legislativa Regional.

Onde o problema do sistema eleitoral açoriano se situa é no facto de estes deputados de representação territorial se encontrarem fundidos 
com os restantes deputados de representação demográfica, preconizados pela regra estatutária nos termos da qual cada ilha elege ainda um determinado número de deputados em função da sua população ou dos eleitores nela residentes.

Isto é, enquanto que o sistema eleitoral norte-americano reserva uma Câmara especial para os seus deputados de representação territorial - o Senado - e outra distinta para os seus deputados de representação demográfica - a Câmara de Representantes, (correspondendo, no sistema alemão, à clivagem entre o Bundesrat e o Bundestag), nos Açores os dois tipos de deputados são fundidos numa câmara só. Tanto assim que não é possível sequer identificar quem são os deputados de representação territorial e quem são os de representação demográfica (a não ser no caso dos deputados eleitos pela ilha do Corvo. Na medida em que são só dois, são necessariamente de representação territorial).

Ora, é aqui, nesta fusão que se situam os problemas da proporcionalidade e da legitimidade democrática contraditória há pouco referidos. Quando falávamos de um problema de proporcionalidade, é, em regra, à proporcionalidade demográfica que nos reportamos. E nada menos do que 18 deputados à Assembleia Legislativa Regional dos Açores são eleitos, não em função de uma proporcionalidade demográfica, mas independentemente dela. Aliás, estes 18 deputados são eleitos exclusivamente em função de uma proporcionalidade física, territorial, insular, o que, numa Assembleia de 52 elementos, não deixa de representar um número extremamente elevado. E deveria ser ainda maior. Em vez de 18, estes deputados de representação territorial deveriam ser 20, já que lhes deveríamos acrescentar dois, em representação da décima ilha dos Açores, da diáspora. E, em boa parte, a contestação de que o actual sistema eleitoral açoriano é alvo decorre das distorções produzidas por esta fusão de duas Câmaras numa só, nomeadamente em termos de proporcionalidade democrática, uma vez que se perde de vista a proporcionalidade territorial, isto é, insular, e todas as atenções se fixam na proporcionalidade demográfica. 
Em termos gerais, portanto a solução é simples: reorganização da Assembleia Legislativa Regional dos Açores em duas Câmaras, uma Câmara Alta, ou Senado, e uma Câmara Baixa, ou de Representantes. Uma Câmara Alta, de representação territorial, onde teriam assento os deputados, eleitos em representação das ilhas que constituem a Região, 18, se tivermos em conta as 9 ilhas do Arquipélago, 20 se lhes adicionarmos 2 deputados em representação da décima ilha açoriana, a diáspora. Uma Câmara Baixa que integraria um número a fixar de deputados, eleitos estritamente segundo critérios de proporcionalidade demográfica. Tal como nos regimes federais, estas Câmaras poderiam reunir individualmente ou conjunto. A Assembleia Legislativa Regional dos Açores, no seu todo, tal como o Congresso, achar-se-ia constituída pela reunião de ambas.

Por fim, torna-se igualmente necessário proceder a uma divisão de competências entre estas duas Câmaras. Segundo a regra tradicional dos sistemas federais, o mais natural será reservar à Câmara Alta um papel na definição das políticas relativas às questões de maior impacto para a comunidade açoriana, tais como a aprovação do Plano e Orçamento, a votação de moções de confiança e de censura ao governo, a revisão do Estatuto de autonomia, a produção legislativa regional, etc. A actuação da Câmara Baixa, para além destas problemáticas, deverá incidir ainda sobre os aspectos de natureza política que se prendem com o debate político regional.

Uma reforma desta natureza não implica um aumento de despesa, ou do peso do aparelho político regional. Pela própria natureza das tarefas que lhe são cometidas, justifica-se, por um lado, o labor, regular e em permanência da Câmara Baixa, e, por outro lado, a sua composição por deputados a tempo inteiro, e em regra, em regime de exclusividade. O mesmo não se verifica em relação à Câmara Alta que, atendendo à natureza e à dimensão das matérias sob sua responsabilidade, necessitaria de reunir, ordinariamente, a espaços regulares e por períodos curtos e, extraordinariamente, sempre que necessário, isto é, sempre que a sua intervenção viesse a ser exigida. Deste modo, e por esta razão, em vez de apontar, sequer, para um registo de exclusivida- 
de, a integração da Câmara Alta torna-se perfeitamente compaginável com o exercício regular de uma actividade profissional.

E para terminar, sublinho apenas dois aspectos adicionais.

Em primeiro lugar, as virtualidades de uma reforma desta natureza, em termos de credibilização da Assembleia, de identificação dos deputados e de aproximação dos eleitos e dos seus eleitores, e de responsabilização dos primeiros perante os segundos pelas atitudes que tomam, pelo trabalho que desenvolvem e pelo modo e sentido em que votam. E, paralelamente, uma reforma desta natureza contribuirá, e muito, para o robustecimento, que se impõe, do legislativo açoriano e para a sua emancipação do executivo. Uma reforma deste tipo aproxima-nos do ideal democrático nos termos do qual a super-estrutura política deve constituir como que um espelho da infra-estrutura social de base à qual importa que esteja ligada, de forma permanente e constante, por uma espécie de vasos comunicantes. E, paralelamente, constituirá uma via sólida e segura para se quebrar a actual quase que asfixia do Parlamento por parte do Governo onde todo o poder político se acabaria por concentrar. Credibilizar, robustecer, autonomizar o parlamento açoriano é tarefa essencial para a democracia e para a autonomia açorianas.

Em segundo lugar, e se a Constituição da República não permitir uma reforma desta natureza, como por vezes se argumenta, então que se proceda à sua revisão de modo a que passe a fazê-lo. Aliás, em nosso entender, é bem altura de se rever todo o regime autonómico açoriano, começando pelo capítulo da Constituição que lhe está dedicado. Na altura em que foi implementada, na segunda metade da década de setenta do século passado, a autonomia açoriana foi pioneira a nível europeu, contexto em que os Açores chegaram a ser visitados por especialistas europeus que ali se deslocaram para poderem conhecer a nossa realidade. No entretanto estagnámos, enquanto as demais autonomias europeias evoluíram, e hoje somos nós que temos que aprender com a sua experiência riquíssima. O regime autonómico açoriano está obsoleto e ultrapassado em termos europeus, urgindo, por isso, refundá-lo. Esta é, porém matéria para uma próxima reflexão. 